\title{
Investigation of wear, groove shape and load capacity of PPS-PTFE hybrid radial ball bearings
}

\author{
Hitonobu KOIKE 1 , Katsuyuki KIDA2a, Toshihiko MATSUMURA², Koshiro MIZOBE ${ }^{2}$, and Yuji KASHIMA ${ }^{3}$ \\ ${ }^{1}$ Kyushu Sangyo University, 2-3-1, Matsukadai, Higashi-ku, Fukuoka, 813-8503, Japan \\ 2 University of Toyama Gofuku 3190, Toyama, 930-8555, Japan \\ ${ }^{3}$ Kashima bearings Inc. 2-9-21 Himesato Nishi-Yodogawa-ku Osaka, 555-0025, Japan
}

\begin{abstract}
In order to improve the radial load capacity and wear loss of the PPS-PTFE hybrid bearings, the groove shape of the PPS inner ring in the PPS-PTFE hybrid bearing was designed based on ceramic bearing's ball radius (r). The rolling contact fatigue tests were performed by using the PPS-PTFE hybrid bearings with the original $\left(\mathrm{r}^{*} 1.0\right)$ and modified $\left(\mathrm{r}^{*} 1.1\right)$ inner rings. The radial load capacity of the bearing using the $\mathrm{r} 1.1$ inner ring was improved $150 \%$ over the capacity of the bearing using the r1.0 inner ring. While the operation temperature of the bearing with the $\mathrm{r} 1.1$ inner ring was stable at $40{ }^{\circ} \mathrm{C}$, that of the bearing with the r1.0 inner ring incresed rapidly over $100{ }^{\circ} \mathrm{C}$ and thermal failure occurred. Moreover, the wear loss of the bearings with the r1.1 inner ring was lower than that of the r1.0. Thus the groove shape influenced the tribology performance of the PPS-PTFE hybrid bearings.
\end{abstract}

\section{Introduction}

Premium plastic bearings of lightweight and custommade for low-volume production are expected for assemblies or equipments in special stuations such as medicine, sky/space, underwater etc. [1-4]. Polyphenylene-sulfide (PPS), which is semi-cystalline thermoplastic polymer, has a glass transition temperature of $90^{\circ} \mathrm{C}$ and a melted tenperature of $278^{\circ} \mathrm{C}$ [5]. Specific density and bending strength are $1.35 \mathrm{~g} / \mathrm{cm}^{3}$ and $142 \mathrm{MPa}$, respectively. With lightweight, good machinability, and corrosion resistance, PPS is promising material for precision-machined custom bearings.

Concerning tribological failures in plastic ball bearings, Marshek stated that overheating, rapid wear or plastic flow occurs on a raceway of bearing's ring [6] when bearing's operation conditions are heavy loads and high rotational speeds. Overheating softens or melts ring, to cause a disassembled bearing. In previous polymer bearing's study, Koike et al stated that the lifespan and wear resistance of the hybrid polymer bearing with the PTFE composite retainer was superior to that without the PTFE composite retainer [7,8]. Also, Mizobe et al. reported that the wear resistance of the PPS bearing with the PTFE composite retainer could be improved under dry condition $[9,10]$.

In this study, the groove shapes of the PPS inner rings of the PPS-PTFE hybrid bearings were designed and then manufactured by lathe machining, in order to improve the load capacity, wear loss and operation temperature for practical applications. Rolling contact fatigue (RCF) tests were performed by using the original and modified PPS-PTFE hybrid bearings under a dry condition.

\section{Experimental Procedure}

\subsection{PPS-PTFE Hybrid Bearing Specimens}

Figure 1 shows the bearing specimen. The PPS-PTFE hybrid bearings were designed based on JIS-B-1512 \#6205. The groove shapes on the bearing's inner rings were designed as the $103 \%$ and $114 \%$ curvature radiuses based on alumina ball radius. Hereafter, the inner rings of $103 \%$ and $114 \%$ curvature radiuses are called as ' $r 1.0$ ' inner ring and ' $r 1.1$ ' inner ring (Fig. 2). The bearing's inner ring and outer ring were produced of PPS from KUREHA EXTRON CO.,LTD. The retainers were produced of PTFE composite [5]. 9 alumina balls were used for each bearing.

\subsection{Rolling Contact Fatigue (RCF)}

Figure 3 shows the illustration of the RCF test machine. The RCF tests were carried out by using the radial-type rolling contact fatigue machine under test conditions of the radial loads ranging from $113 \mathrm{~N}$ to $333 \mathrm{~N}$ at room temperature. Rotation speeds were 600 and $3000 \mathrm{rpm}$. The RCF tests were continued until $1.0 \times 10^{6}$ fatigue cycles or bearing's failure. The contact surface of each tested bearing's specimen was observed by a Laser Confocal Microscope (LCM). The operation temperature

a Corresponding author: kida@eng-u.toyama.ac.jp 


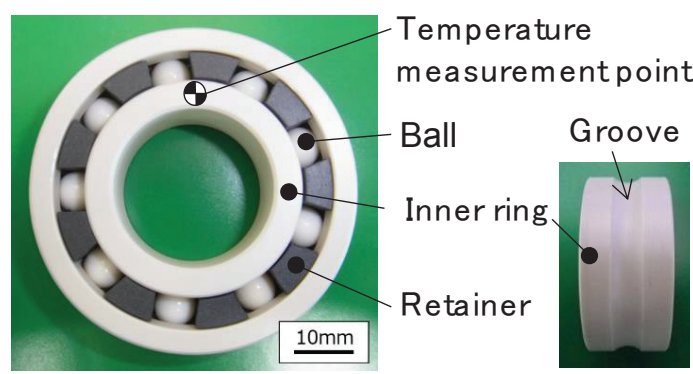

Fig. 1. PPS-PTFE radial bearing.

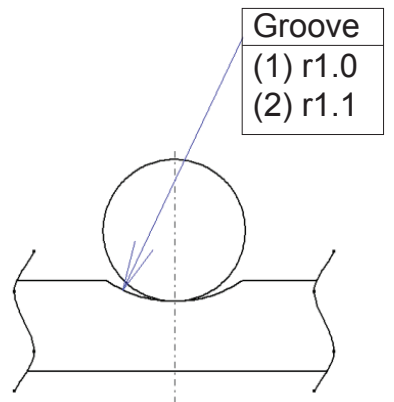

Fig. 2. Truck curvature radius of inner rings of bearings.

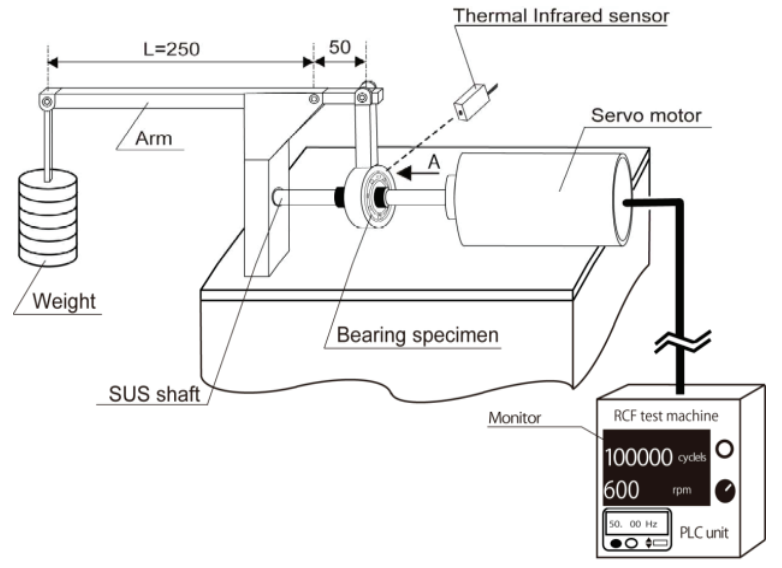

Fig. 3. Radial-type rolling contact fatigue machine.

of the bearing's inner ring was measured by a thermal infrared sensor. The temperature was measured on the inner ring surface from rotating axis direction as shown in Figure 3. In order to calculate wear loss of the bearing's part, the weights of the inner ring, outer ring and retainer of PPS-PTFE hybrid radial bearing were measured by a Shimadzu electric balance.

\section{Experimental results and discussion}

\subsection{RCF test results}

Figure 4 shows the load capacities of the bearings with the r1.0 and r1.1 inner rings. The red circle ( $\circ$ ) represents no failure at $1.0 \times 10^{6}$ fatigue cycles. The cross mark $(\times)$ represents the bearing's rotation stop due to thermal deformation during RCF testing. When the test conditions were $600 \mathrm{rpm}-333 \mathrm{~N}$ or $3000 \mathrm{rpm}-162 \mathrm{~N}$, the thermal deformation of the hybrid bearing with the r1.0 inner ring
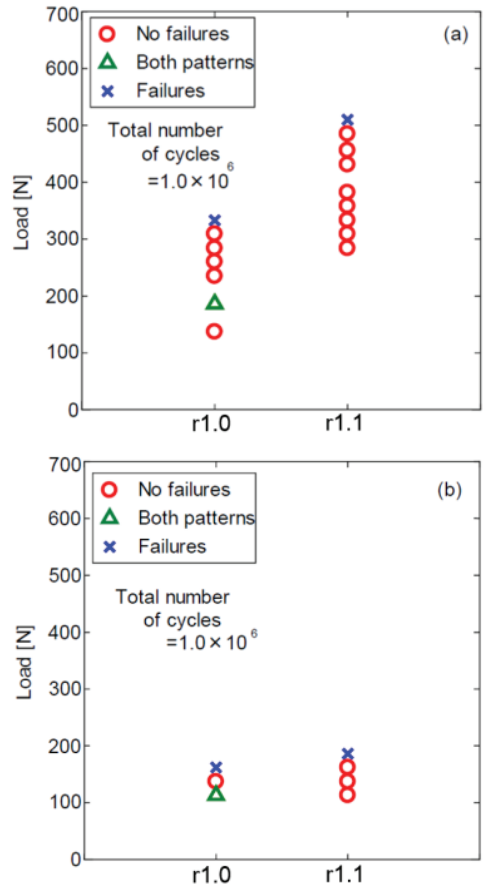

Fig. 4. Load capacity of r1.0 and r1.1 bearings ; (a) at 600rpm and (b) at 3000 rpm.

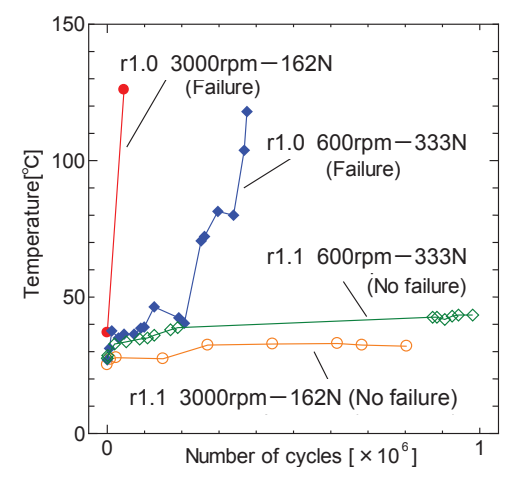

Fig. 5. Transition of operation temperature of r1.0 and r1.1 bearings at $600 \mathrm{rpm}$.

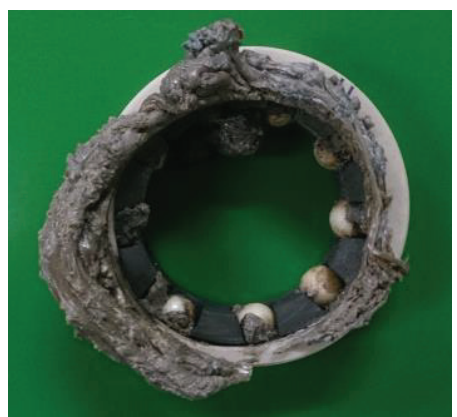

Fig. 6. Thermal failure at $3000 \mathrm{rpm}$ and $162 \mathrm{~N}$ load.

occurred. The radial load capacity of the PPS-PTFE bearings with the 1.1 inner ring during the RCF test at $600 \mathrm{rpm}$ was improved $150 \%$ of the PPS-PTFE bearings with the r1.0 inner ring. It was found that the load capacity of the bearing with the r1.1 inner ring was higher than that of the r1.0 ring when rotational speeds were $600 \mathrm{rpm}$ and $3000 \mathrm{rpm}$. Figure 5 shows the transition of operation temperature of the r1.0 and the r1.1 inner rings during the RCF tests at $600 \mathrm{rpm}$. 

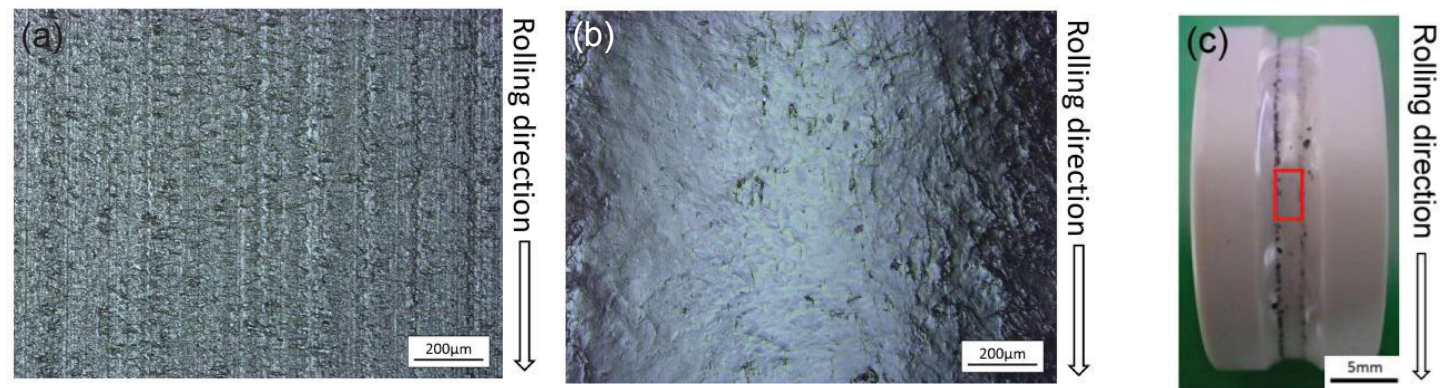

Fig. 7. Specimen surface of r1.0; (a) before the test, (b) after the test at $600 \mathrm{rpm}-284 \mathrm{~N}$, and (c) macro image of (b). Note that the red rectangle in (c) means observation area.
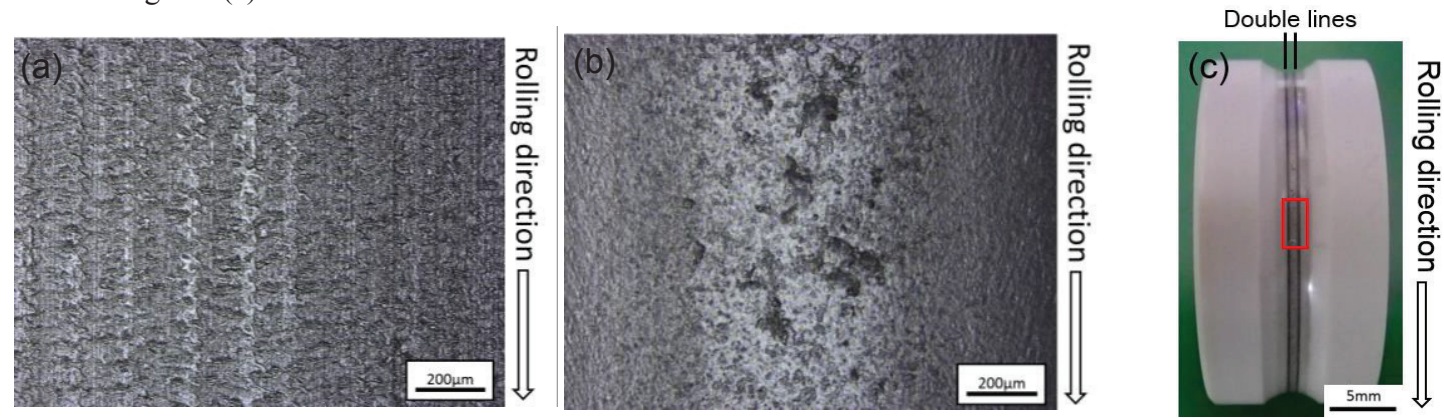

Fig. 8. Specimen surface of r1.1 ; (a) before the test and (b) after the test at $600 \mathrm{rpm}-284 \mathrm{~N}$, and (c) macro image of (b). Note that the red rectangle in (c) means observation area.

While the temperature of the PPS-PTFE bearing with the r1.1 inner ring was approximately $40^{\circ} \mathrm{C}$ during the test at $600 \mathrm{rpm}$ under $333 \mathrm{~N}$ load, the temperature of the PPSPTFE bearing with the r1.0 inner ring increased rapidly during the early operation stage. The rotation of the PPSPTFE bearing with the r1.0 inner ring was stopped due to thermal deformation as shown in Figure 6.

\subsection{Contact Surface}

Figures 7 show the LCM images of the r1.0 inner ring raceway of the PPS-PTFE bearing before and after $1.0 \times 10^{6}$ fatigue cycles under $284 \mathrm{~N}$ radial load at 600 $\mathrm{rpm}$. The r1.0 inner ring raceway surface was worn and flattened during the tests due to the rolling contact. Figures 8 show the LCM images of the r1.1 inner ring raceway of the PPS-PTFE bearing before and after $1.0 \times 10^{6}$ fatigue cycles. The dark gray double lines were observed on the r1.1 inner ring raceway (Fig. 8c). Because of the tribo-film accumulated along this double lines, the bearing rotated smoothly during the RCF test.

\subsection{Wear Loss}

Figure 9 shows the wear loss of the each part in the PPSPTFE bearing after $1.0 \times 10^{6}$ fatigue cycles. The wear losses of the inner ing ( $\circ$ ) and the outer ring ( $\square$ ) in the r1.1 PPS-PTFE bearing were lower than that of r1.0. The tribo-film was formed on the raceway of $\mathrm{r} 1.1$ inner ring rather than on the raceway of r1.0 inner ring. Therefore, the deformation and friction heat of the inner ring

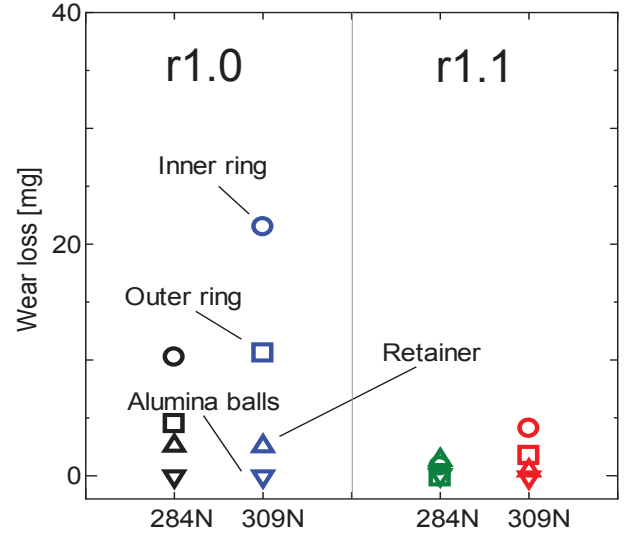

Fig. 9. Wear loss of the PPS-PTFE bearings (600 rpm).

raceway surface decreased. Thus, it is found that the difference of the groove radius values between the r1.1 and the r1.0 influenced tribo-film formation.

\section{Conclusions}

In order to improve the load capacity and wear loss of the radial PPS-PTFE hybrid alumina ball bearings, the r1.0 and r1.1 groove shapes of the PPS inner rings were designed. The rolling contact fatigue tests were carried out under a dry condition at 600 and 3000 rpm rotation speeds. The important results obtained from this work can be summarized as follows: 
(1) The radial load capacity of the PPS-PTFE hybrid bearings with the r1.1 inner ring during the RCF test at $600 \mathrm{rpm}$ could be improved $150 \%$ compared to the PPS-PTFE hybrid bearings with the r1.0 inner ring.

(2) While the PPS inner ring with the r1.0 groove shape was deformed at $333 \mathrm{~N}$ radial load, the PPS inner ring with the $\mathrm{r} 1.1$ radius raceway was achieved at $1.0 \times 10^{6}$ fatigue cycles.

(3) The wear loss and operation temperature of the PPSPTFE hybrid bearings with the r1.1 inner ring were lower than those of the $\mathrm{r} 1.0$ when the test conditions were $113-333 \mathrm{~N}$ radial load and $600 \mathrm{rpm}$ rotational speed.

This work was supported by JKA and its promotion funds from KEIRIN RACE (No. 27-124, 28-138).

\section{References}

1. T. A. Stolarski, Advanced in Composite Tribology edited by K. Friedrich (Elsevier Science Publishers B.V., 1993), Chapter 17.

2. K. Friedrich, G. Theiler and P. Klein, In: SinhaSK, BriscoeBJ, editors. Polymer Tribology (Imperial College Press, London UK, 2009), 375-415.

3. V. Buck, Trib. Int'1, 19, 1, 25-28, (1986).

4. M. Harrass, K. Friedrich, A. A. Almajid, Trib. Int'l, 43, 635-646, (2010).

5. K. Mizobe, T. Honda, H. Koike, E. C. Santos, Y. Kashima and K. Kida, Adv. Mat. Res., 683, 90-93, (2013).

6. K. M. Marshek, Wear, 52, 141-146, (1979).

7. H. Koike, K. Mizobe, S. Oyama, Y. Kashima, and K. Kanemasu, Adv. Mat. Res., 683, 385-390, (2013).

8. H. Koike, K. Kida, K. Mizobe, X. Shi, S. Oyama, and Y. Kashima, Trib. Int'1, 90, 77-83, (2015).

9. K. Mizobe, T. Matsumura, Y. Kashima, and K. Kida, Key Eng. Mat. , 703, 197-201, (2016).

10. K. Mizobe, H, Honda, H, Koike, E. C. Santos, K. Kida, Y. Kashima, Adv. Mat. Res. 566, 157-161, (2012). 